\title{
Validity and reliability of the Cognitive Complaints in Bipolar Disorder Rating Assessment (COBRA) in Brazilian bipolar patients
}

\author{
Validade e fidedignidade da Escala de Disfunções Cognitivas no Transtorno \\ Bipolar (COBRA) em pacientes bipolares brasileiros
}

Flávia M. Lima, ${ }^{1,2}$ Taiane A. Cardoso, ${ }^{3}$ Sílvia D. Serafim,,$^{1,2}$ Dayane S. Martins,,$^{1,4}$ Brisa Solé, ${ }^{5}$ Anabel Martínez-Arán, ${ }^{5}$ Eduard Vieta, ${ }^{5}$ Adriane R. Rosa ${ }^{1,2,6}$

\begin{abstract}
Introduction: In Brazil, there is no valid instrument to measure subjective cognitive dysfunction in bipolar disorder. The present study analyzed the psychometric properties of the Cognitive Complaints in Bipolar Disorder Rating Assessment (COBRA) in Brazilian bipolar patients. We further investigated the relationship between the COBRA, objective cognitive measures, and illness course variables.

Methods: The total sample $(\mathrm{N}=150)$ included 85 bipolar disorder patients and 65 healthy controls. The psychometric properties of the COBRA (e.g., internal consistency, concurrent validity, discriminative validity, factor analyses, ROC curve, and feasibility) were analyzed.

Results: The COBRA showed a one-factor structure with very high internal consistency (Cronbach's alpha $=0.890$ ). Concurrent validity was indicated by a strong correlation with the cognitive domain of the FAST $(r=0.811, p<0.001)$. Bipolar patients experienced greater cognitive complaints (mean $=14.69$; standard deviation $[S D]=10.03$ ) than healthy controls (mean $=6.78$; $\mathrm{SD}=5.49 ; \mathrm{p}<0.001)$, suggesting discriminative validity of the instrument. No significant correlations were found between the COBRA and objective cognitive measures. Furthermore, higher COBRA scores were associated with residual depressive $(r=0.448 ; \mathrm{p}<0.001)$ and manic $(r=0.376 ; \mathrm{p}<0.001)$ symptoms, number of depressive episodes $(r=0.306 ; p=0.011)$, number of total episodes $(r=0.256 ; \mathrm{p}=0.038)$, and suicide attempts $(r=0.356 ; \mathrm{p}=0.003)$.

Conclusion: The COBRA is a valid instrument to assess cognitive complaints, and the combined use of subjective-objective cognitive measures enables the correct identification of cognitive dysfunctions in bipolar disorder.
\end{abstract}

Keywords: Bipolar disorder, cognition, neuropsychological tests, cognitive complaints.

\section{Resumo}

Introdução: No Brasil, não existem instrumentos válidos para medir a disfunção cognitiva subjetiva no transtorno bipolar. O presente estudo analisou as propriedades psicométricas da Escala de Disfunções Cognitivas no Transtorno Bipolar (COBRA) em uma amostra brasileira de pacientes bipolares. Adicionalmente, investigamos a relação entre a COBRA, medidas cognitivas objetivas e curso da doença.

Métodos: A amostra total $(n=150)$ incluiu 85 pacientes com transtorno bipolar e 65 controles saudáveis. As propriedades psicométricas da COBRA (consistência interna, validade concorrente, validade discriminativa, análise fatorial, curva ROC e fidedignidade) foram analisadas.

Resultados: A COBRA apresentou estrutura de um fator com alta consistência interna (alfa de Cronbach $=0,890$ ). A validade concorrente ficou demonstrada pela forte correlação com o domínio cognitivo da FAST $(r=0,811, p<0,001)$. Pacientes bipolares tiveram mais queixas cognitivas [média $=14,69$; desvio padrão $(D P)=10,03$ ] que os controles (média $=6,78 ; \quad D P=5,49$; $p<0,001)$, sugerindo a validade discriminativa do instrumento. Não houve correlação significativa entre a COBRA e medidas cognitivas objetivas. Além disso, escores mais altos na COBRA estiveram associados com sintomas residuais depressivos $(r=0,448 ; \mathrm{p}<0,001)$ e maníacos $(r=0,376 ; \mathrm{p}<0,001)$, número de episódios depressivos $(r=0,306 ; \mathrm{p}=0,011)$, número de episódios totais $(r=0.256 ; \mathrm{p}=0.038)$ e tentativas de suicídio $(r=0,356$; $\mathrm{p}=0,003)$.

Conclusão: A COBRA é um instrumento válido para avaliar queixas cognitivas, e o uso combinado das medidas cognitivas subjetivas-objetivas possibilita a correta identificação das disfunções cognitivas no transtorno bipolar.

Descritores: Transtorno bipolar, cognição, testes neuropsicológicos, queixas cognitivas.

${ }^{1}$ Laboratório de Psiquiatria Molecular, Hospital de Clínicas de Porto Alegre (HCPA), Porto Alegre, RS, Brazil. ${ }^{2}$ Programa de Pós-Graduação em Psiquiatria e Ciências do Comportamento, Universidade Federal do Rio Grande do Sul (UFRGS), Porto Alegre, RS, Brazil. ${ }^{3}$ Programa de Pós-Graduação em Saúde e Comportamento, Universidade Católica de Pelotas (UCPel), Pelotas, RS, Brazil. ${ }^{4}$ Centro Universitário Ritter dos Reis, Porto Alegre, RS, Brazil. ${ }^{5}$ Centro de Investigación Biomédica en Red de Salud Mental (CIBERSAM), Hospital Clinic, Universitat de Barcelona, Barcelona, Catalonia, Spain. ${ }^{6}$ Departamento de Farmacologia, UFRGS, Porto Alegre, RS, Brazil.

Submitted Sep 29 2017, accepted for publication Feb 062018.

Suggested citation: Lima FM, Cardoso TA, Serafim SD, Martins DS, Solé B, Martínez-Arán A, et al. Validity and reliability of the Cognitive Complaints in Bipolar Disorder Rating Assessment (COBRA) in Brazilian bipolar patients. Trends Psychiatry Psychother. 2018;40(2):170-178. http://dx.doi.org/10.1590/2237-60892017-0121 


\section{Introduction}

Cognitive dysfunction in bipolar disorder (BD) occurs across several domains, including attention, verbal memory and executive function.1,2 These deficits are not only present during acute mood episodes, but persist, in some degree, into periods of remission. 3,4 In addition, cognitive dysfunction may predict functional impairment ${ }^{5,6}$ and treatment adherence. 7,8 Thus, the correct identification and treatment of cognitive dysfunction in BD is critical and would help improve functioning and quality of life for patients with BD. 9

In the last two decades, cognitive function has become one of the most important construct to be evaluated in psychiatry, both clinically and in research. Indeed, emerging evidence has highlighted the relevance of assessing cognitive performance in BD. ${ }^{10,11}$ However, the ideal methodology for assessing cognition in mental illness is still subject of debate in the literature. Whereas objective cognitive measures (e.g., neuropsychological tests) allow us to assess cognitive performance of an individual as compared to the normative population, subjective cognitive measures tend to assess the subject's cognitive function in comparison to their own premorbid levels. ${ }^{10-12}$ Furthermore, the patient's perception of their cognitive function is an important issue and should be considered. Therefore, an adequate assessment of cognition requires not only objective neuropsychological tests but also subjective cognitive measures. ${ }^{10}$

Although there are several instruments evaluating subjective cognitive dysfunction in patients with mental disorders, ${ }^{13-16}$ most of them do not specifically detect cognitive deficits experienced by patients with $B D$. In this context, the Cognitive Complaints in Bipolar Disorder Rating Assessment (COBRA) was carefully designed to assess cognitive difficulties associated with the main deficits experienced by patients with $B D$ as reported in the literature. ${ }^{11}$ Currently, the COBRA is available in distinct languages (such as Spanish, English, French Chinese, Danish, Japanese) and has been used in both research and clinical practice in various cultures. ${ }^{11,12,17-19}$

In Brazil, there is no clinically feasible screening scale to assess cognitive difficulties in $B D$, indicating the importance to validate instruments in this regard. The main aim of the current study was to examine the psychometric properties of the COBRA among Brazilian patients with BD. In addition, we investigated the relationship between the COBRA scale, neuropsychological tests, and the course of the illness.

\section{Methods}

\section{Participants}

Eighty-five patients with BD were recruited from the Programa de Atendimento do Transtorno de Humor Bipolar (PROTHABI), at Hospital de Clínicas de Porto Alegre, in southern Brazil, between October 2015 and July 2017. The inclusion criteria were: 1) having a diagnosis of BD according to the Diagnostic and Statistical Manual of Mental Disorders, 5th edition (DSM$5)$; 2) being 18 to 70 years old; 3) meeting criteria for euthymia for at least one month previous to the assessment, defined as a score $\leq 7$ on the Hamilton Depression Rating Scale (HAM-D) ${ }^{20}$ and the Young Mania Rating Scale (YMRS). ${ }^{21}$ Exclusion criteria were: 1) having any medical or comorbid psychiatric condition affecting neuropsychological performance and current drug or alcohol dependence or abuse; and 2) having undergone electroconvulsive therapy within the past year.

Sixty-five healthy controls who had no current or previous history and no first-degree family history of a major psychiatric disorder, including dementia or mental retardation, assessed by the non-patient version of the Structured Clinical Interview for DSM-IV-TR (SCID), were recruited from the general population within the catchment area of Hospital de Clínicas de Porto Alegre.

This study was approved by the ethics committee of Hospital de Clínicas de Porto Alegre. Following verbal description of the study objectives and details, all participants signed a written informed consent form.

\section{Assessment}

\section{Clinical and demographic features}

All participants' demographic, clinical and pharmacological data were obtained through a structured interview and from medical records. The 17-item HAM-D ${ }^{20}$ and the YMRS $^{21}$ were administered by trained raters to assess depressive and manic symptoms, respectively.

\section{Functional status}

The overall functional outcome was assessed using the Functioning Assessment Short Test (FAST), an instrument widely used in patients with BD. This scale includes 24 items that evaluate six functional domains (autonomy, occupational functioning, cognitive functioning, financial issues, interpersonal relationships, and leisure time). The higher the score, the greater the disability. ${ }^{22}$

\section{Subjective cognitive measure}

The COBRA is a 16 -item self-report instrument that allows to measure subjective cognitive difficulties 
including executive function, processing speed, working memory, verbal learning and memory, attention/ concentration, and mental tracking. All items are rated using a 4-point scale: $0=$ never, $1=$ sometimes, 2 = often, and 3 = always (see Portuguese and English versions in Appendix 1). The total score is obtained by adding up the scores of every item. The higher the score, the higher the number of subjective complaints. ${ }^{11}$

The linguistic adaptation of the COBRA started with a document in Portuguese obtained by the translation/ back-translation method. The items not resulting in appropriate wording equivalence with the original text were analyzed by the team of investigators and the translators until they agreed upon an appropriate expression. Subsequently, two bilingual authors (TAC and $A R R$ ) evaluated the degree of equivalence between the original English and the Portuguese version.

\section{Objective cognitive measure}

Based on the consensus of the International Society for Bipolar Disorders-Battery for Assessment of Neurocognition (ISBD-BANC), ${ }^{23}$ all participants completed a comprehensive neuropsychological battery in order to assess different cognitive domains, as follows:

- Processing speed: Phonemic Verbal Fluency $(\mathrm{F}-\mathrm{A}-\mathrm{S})^{24}$ and Trail Making Test-Part A (TMT-A) ${ }^{25}$;

- Working memory: Letter-Number Sequencing Subtest WAIS-III (LNS) ${ }^{26,27}$;

- Verbal learning and memory: Hopkins Verbal Learning Test - Revised (HVLT-R) ${ }^{28}$;

- Executive functions: Stroop Color-Word Test $(\mathrm{SCWT})^{29}$ and Trail Making Test-Part B $(\text { TMT-B) })^{25}$;

- Attention: Continuous Performance Test Identical Pairs (CPT-IP);

- Social cognition: Reading the Mind in the Eyes Test - Revised (RMET-R) ${ }^{30}$;

- Estimated intelligence quotient (IQ): Wechsler Abbreviated Scale of Intelligence (WASI) vocabulary and matrix reasoning subtests. ${ }^{31,32}$

\section{Validity and reliability assessment}

Internal consistency reliability of the COBRA was assessed using Cronbach's a coefficient. Concurrent validity was assessed in three ways: 1 ) to examine the relationship between COBRA results and the cognitive domain of the FAST; 2) to investigate the association between the COBRA and objective cognitive measures (neuropsychological battery); and 3 ) to investigate possible correlations between the COBRA and course of the illness. Validity as a discriminative measure to detect differences between patients with BD and healthy controls was analyzed using parametric independent $t$-tests. The optimal point for the COBRA was determined by means of a receiver operating characteristic (ROC) curve. An exploratory factor analysis by the principal axis factoring method (quartimax with Kaiser normalization) was performed to describe the internal structure of the COBRA. Finally, feasibility was described as the percentage of patients and controls who did respond to the questionnaire in its entirety.

\section{Statistical analysis}

Statistical analysis was performed using the Statistical Package for the Social Sciences (SPSS) for Windows, version 18.0. Internal consistency was assessed using Cronbach's alpha. Spearman's correlation coefficients were calculated to examine the possible relationship between the COBRA, FAST, neuropsychological and clinical variables. Group comparisons (patients and controls) were made using parametric $t$-tests. The rotation was performed using the quartimax method and the ROC curve was used to detect the optimal point to discriminate between patients and controls.

\section{Results}

A total of 150 subjects ( 85 patients with BD and 65 healthy volunteers) were included in the study. Sixtyone $(71.8 \%)$ patients and $46(78.0 \%)$ controls were women $(p=0.240)$. The mean age of the patients was 49.60 (12.88) years, and that of the controls was 45.85 $(15.68)$ years $(p=0.121)$. Other sociodemographic and clinical characteristics of the sample are shown in Table 1.

\section{Internal consistency}

The internal consistency coefficient obtained was high, with Cronbach's alpha $=0.890$ for the total 16 item scale, suggesting that the items are sufficiently homogeneous.

\section{Associations between COBRA and FAST}

A strong correlation was found between the COBRA total score and the cognitive domain of the FAST scale, indicating the concurrent validity of the instrument ( $r=0.811, \mathrm{p}<0.001 ;$ Figure 1$)$.

\section{Associations between subjective and objective cognitive measures}

Spearman correlations were performed to assess the relationship between subjective and objective cognitive measures in both groups. No significant correlation was found between the COBRA and neuropsychological 
tests among the patients ( $p$-values $>0.107$ ). In the control group, a negative significant correlation was found between the COBRA and HVLT-R ( $p=0.006$; other p-values $>0.072$ ).

\section{Associations between subjective cognitive measures and course of illness}

The COBRA was positively correlated with total number of mood episodes $(r=0.256 ; p=0.038)$, number of depressive episodes $(r=0.306 ; p=0.011)$, number of suicide attempts $(r=0.356 ; \mathrm{p}=0.003)$, residual depressive symptoms $(r=0.448 ; \mathrm{p}<0.001)$, and manic symptoms ( $r=0.376 ; \mathrm{p}<0.001$; Table 2$)$.

\section{Validity as a discriminative measure to detect differences between patients with BD and healthy controls}

Patients with BD showed higher COBRA total scores (mean=14.69; standard deviation $[S D]=10.03$ ) than healthy controls (mean=6.78; $\mathrm{SD}=5.49 ; \mathrm{p}<0.001$; Figure 2).

\section{ROC curve}

We analyzed the scale's ability to discriminate between patients and controls by means of the diagnostic performance or ROC curve. The area under the curve was 0.752 (95\% confidence interval [95\%CI]

Table 1 - Sociodemographic characteristics of the sample and clinical characteristics of patients with BD

\begin{tabular}{lccc}
\hline & $\begin{array}{c}\text { Controls } \\
(\mathbf{n = 6 5 )}\end{array}$ & $\begin{array}{c}\text { Patients with BD } \\
(\mathbf{n = 8 5})\end{array}$ \\
\hline Sex (female), $\mathrm{n}(\%)$ & $46(78.0)$ & $61(71.8)$ & $\mathbf{p}$ \\
Age (years) & $45.85(15.68)$ & $49.60(12.88)$ & 0.240 \\
Years of education & $14.71(4.08)$ & $10.67(4.02)$ & 0.121 \\
Married, $\mathrm{n}(\%)$ & $30(46.2)$ & $38(45.8)$ & 0.001 \\
Employed, $\mathrm{n}(\%)$ & $30(46.2)$ & $19(22.9)$ & 0.964 \\
Age at onset (years) & & $33.63(12.53)$ \\
Number of hospitalizations & & $4.21(5.17)$ \\
Number of (hypo)manic episodes & & $6.25(4.93)$ \\
Number of depressive episodes & & $6.12(5.14)$ \\
Number of total episodes & & $12.48(8.71)$ \\
Duration of illness (years) & & $15.66(9.54)$ \\
Number of suicide attempts & & $1.27(1.44)$ \\
Psychotic symptoms at first episode & & $48(61.5 \%)$ \\
HAM-D score & & $3.52(2.12)$ \\
YMRS score & & $1.17(1.44)$ \\
\hline
\end{tabular}

Data presented as mean (standard deviation), unless otherwise specified.

$\mathrm{BD}=$ bipolar disorder; HAM-D = Hamilton Depression Rating Scale; SD = standard deviation; YMRS = Young Mania Rating Scale.

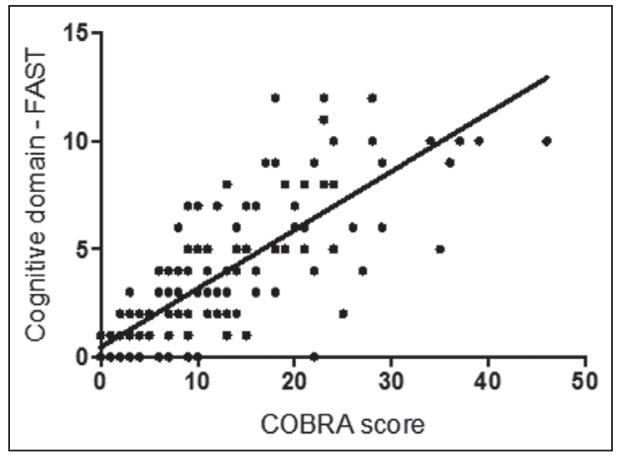

Figure 1 - Concurrent validity of the COBRA. Spearman correlation between COBRA and the cognitive domain score of FAST scale $(r=0.811 ; p<0.001)$. COBRA = Cognitive Complaints in Bipolar Disorder Rating Assessment; FAST = Functioning Assessment Short Test.
Table 2 - Spearman's correlation coefficients between COBRA and the course of bipolar disorder

\begin{tabular}{lc}
\hline & $\begin{array}{c}\text { COBRA score } \\
\boldsymbol{r}(\mathbf{p})\end{array}$ \\
\hline Age & $0.052(0.640)$ \\
Age at onset & $0.026(0.821)$ \\
Total number of episodes & $0.256(0.038)$ \\
Number of depressive episodes & $0.306(0.011)$ \\
Number of manic episodes & $0.161(0.191)$ \\
Number of hospitalizations & $0.005(0.966)$ \\
Number of suicide attempts & $0.356(0.003)$ \\
Duration of illness & $0.136(0.233)$ \\
HAM-D score & $0.448(<0.001)$ \\
YMRS score & $0.376(<0.001)$ \\
\hline
\end{tabular}

COBRA = Cognitive Complaints in Bipolar Disorder Rating Assessment; HAM-D = Hamilton Depression Rating Scale; SD = standard deviation; YMRS = Young Mania Rating Scale. 
0.674-0.829), i.e., close to 1 , indicating good capacity. The discriminative capacity analysis indicated that a score of 10 obtains the best balance between sensitivity $(64.7 \%)$ and specificity (72.3\%; Figure 3 ).

\section{Factor analysis}

The study of the internal structure of the COBRA, after rotation (using the quatrimax method), determined a three-factor structure, as shown in Table 3. However, only two items were loaded in the second factor, and one item in the third factor. As values loaded in the second factor and third factor were very close to the

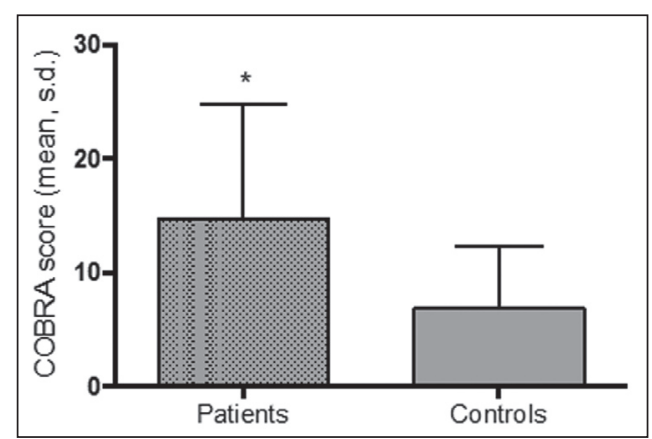

Figure 2 - Mean and standard deviation of COBRA between patients and controls. COBRA $=$ Cognitive Complaints in Bipolar Disorder Rating Assessment. * $\mathrm{p}<0.001$.

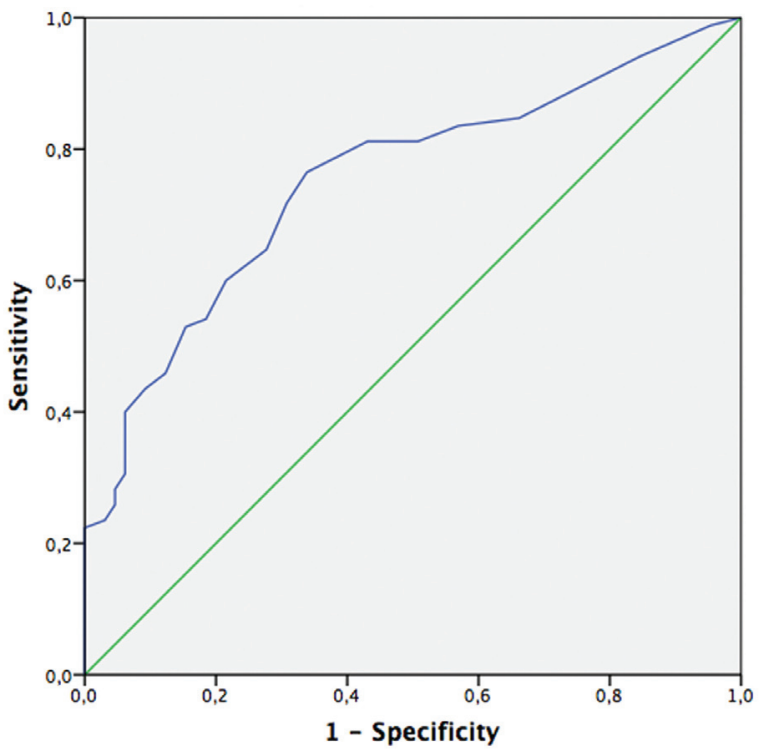

Figure 3 - ROC curve between patients and controls. The area under the curve was 0.752 (95\%CI 0.674-0.829). Cut-off point 10 indicates the best balance between sensitivity $(64.7 \%)$ and specificity $(72.3 \%) .95 \% \mathrm{CI}=95 \%$ confidence interval; ROC = receiver operating characteristic. first load, we confirmed the original one-factor structure with $38.42 \%$ of the total variance.

\section{Feasibility}

Finally, the results showed a high feasibility of the COBRA, since the totality of participants answered all items of the instrument.

\section{Discussion}

The results of the present study demonstrated that the COBRA is a valid method to assess cognitive complaints in Brazilian patients with BD. The instrument exhibited satisfactory psychometric properties, with very high internal consistency and convergent validity as indicated by a strong correlation with the cognitive domain of the FAST. As expected, COBRA total scores were higher in patients compared to healthy controls, suggesting the discriminative validity of the instrument. The cut-off point to discriminate subjective cognitive function between patients and controls was the same found in the Spanish validation study $(>10)$ and similar to the Chinese study $(>11)$. Furthermore, the COBRA presented a one-factor structure, which means that patients tend to perceive their deficits as a global cognitive dysfunction rather than to discriminate deficits in specific cognitive domains. Our finding is consistent with previous validation studies with BD in other countries. ${ }^{11,12,17,19}$ The Portuguese version of

Table 3 - Factor loadings on the COBRA

\begin{tabular}{lccc}
\hline & \multicolumn{3}{c}{ Factor } \\
\cline { 2 - 4 } & $\mathbf{1}$ & $\mathbf{2}$ & $\mathbf{3}$ \\
\hline Item 5 & 0.722 & & \\
Item 15 & 0.700 & & \\
Item 16 & 0.677 & & \\
Item 6 & 0.668 & & \\
Item 14 & 0.666 & & \\
Item 12 & 0.623 & & \\
Item 11 & 0.610 & & \\
Item 8 & 0.601 & & \\
Item 13 & 0.575 & & \\
Item 7 & 0.573 & & \\
Item 1 & 0.568 & & \\
Item 10 & 0.469 & & \\
Item 9 & 0.402 & & \\
Item 4 & 0.473 & 0.591 & \\
Item 3 & 0.516 & 0.534 & \\
Item 2 & 0.479 & & \\
\hline
\end{tabular}

COBRA $=$ Cognitive Complaints in Bipolar Disorder Rating Assessment. Extraction method: principal axis factoring (quartimax rotation with Kaiser normalization). 
the COBRA is now ready and available to be used as a subjective cognitive measure in clinical practice and research settings.

The weak correlation found between the COBRA and neuropsychological tests in the current study is in agreement with previous findings. For instance, the Spanish study showed significant correlations between the COBRA and some neuropsychological tests, particularly in single measures related to executive function, working memory, verbal, and visual memory. ${ }^{11}$ A recent research in Japan observed no association between the COBRA and objective neurocognitive battery, except for COBRA and processing speed. ${ }^{19}$ Xiao et al. $^{17}$ did not find relationships between the COBRA and the Montreal Cognitive Assessment (MoCA) total score. However, significant correlations were found between the COBRA and single measures related to executive function and verbal memory. A study conducted in Denmark ${ }^{12}$ showed a poor association between objective cognitive measures and the COBRA. In particular, COBRA total scores correlated with working memory and executive skills on the neuropsychological tests and on the Screen for Cognitive Impairment in Psychiatry (SCIP). In contrast, we found a correlation between the COBRA and verbal memory in healthy controls. Possibly, some patients with BD have more difficulties in reporting correctly their cognitive deficits or have more difficulties in expressing their cognitive deficits. Taken together, these findings support the idea that subjective cognitive measures are not a direct expression of objective cognitive measures. ${ }^{18}$ In particular, the COBRA is a self-report instrument expressing patients' opinion of their cognitive difficulties in daily lives, which is not always congruent with results obtained by objective neuropsychological tests that compare patients' performance with a normative group, and therefore reflect different aspects of cognition.

In addition, as objective and subjective cognitive measures may capture somewhat different processes, some authors have suggested that simple correlational analysis between overall scores of subjective cognitive measures and neuropsychological tests may limit the understanding of this disagreement. ${ }^{10}$ In this sense, Miskowiak et al. ${ }^{10}$ proposed a novel methodology to quantify the degree and direction of the subjectiveobjective discrepancy, as well to explore predictors of discrepancy. Their findings indicated that some patients seem to have a relatively accurate sense of their cognitive abilities, whereas others may overreport or underreport cognitive difficulties. In particular, patients with more mood symptoms, greater illness chronicity, BD type II, and male gender showed greater subjective than objective cognitive impairment, whereas patients with high premorbid IQ underreported objective cognitive impairment. Further studies are required to investigate concordance and discrepancy between subjective and objective cognitive measures as this understanding could guide the clinical assessment and treatment of cognitive dysfunction in BD.

Another interesting finding of the present study was that patients with more subsyndromal depressive and manic symptoms experienced greater cognitive complaints, suggesting that mood symptoms may influence self-assessment of cognitive difficulties. The impact of depressive symptoms on subjective cognitive measures has been consistently demonstrated in many studies. ${ }^{11,18}$ For instance, using a multiple regression analysis, Ott et al. ${ }^{18}$ identified depressive symptoms as the best predictor of subjective cognitive dysfunction in a unipolar disorder sample. Indeed, there is a trend toward increased subjective cognitive complaints alongside increased depressive symptomatology. A possible explanation for these findings is that depressive symptoms, albeit residual, lead to a negative perception of cognitive ability in these individuals, affecting their functioning. Conversely, it is possible to speculate that the patient's perception of themselves as less competent may contribute to the worsening of depressive symptoms.

Furthermore, other clinical variables such as number of depressive episodes, number of total episodes, and suicide attempts were strongly correlated with overall COBRA score. However, the relation between subjective cognitive measures and clinical course of the illness is complex. Probably, those patients with more illness chronicity represent a subgroup with poor insight, which, in turn, may affect their self-report cognitive assessment. To sum up, these findings highlight that subclinical depressive symptoms, among other variables, may act as mediators or confounders, affecting the poor association between objective and subjective cognitive measures.

The present study has a number of limitations. First, this was a cross-sectional study, conducted in a tertiary hospital, where participants tend to present more severe symptoms, which may limit the generalization of the findings. Second, all our patients were on pharmacological treatment, which may have affected the cognitive assessment. Third, as there is not a gold standard instrument to assess subjective cognitive function in Brazil, we used the cognitive domain of the FAST to perform convergent validity analysis.

In conclusion, our findings showed that the Portuguese version of the COBRA is a valid and feasible instrument to assess cognitive complaints in BD. As objective and subjective measures assess distinct 
aspects of cognition, the combined use of subjectiveobjective instruments may greatly contribute to improve our knowledge of the nature and extent of cognitive dysfunctions in BD. Finally, the correct identification of cognitive dysfunctions would allow us to implement specific therapeutic strategies to improve cognition and functioning in $B D$.

\section{Acknowledgements}

This study received financial support from Conselho Nacional de Desenvolvimento Científico e Tecnológico (CNPq) and Fundo de Incentivo à Pesquisa e Eventos (FIPE-HCPA; 12-0352). Flávia M. Lima and Sílvia D. Serafim are scholarship recipients from Coordenação de Aperfeiçoamento de Pessoal de Nível Superior (CAPES). Taiane A. Cardoso is the recipient of a scholarship from CNPq. Dayane S. Martins is the recipient of a scholarship from Fundação de Amparo à Pesquisa do Estado do Rio Grande do Sul (FAPERGS).

\section{Disclosure}

Anabel Martínez-Arán has served as a speaker or advisor for Bristol-Myers Squibb, Otsuka, Lundbeck, and Pfizer. Eduard Vieta has received grants, continuing medical education-related honoraria, or consulting fees from Alexza, Almirall, AstraZeneca, Bristol-Myers Squibb, Cephalon, Eli Lilly, Ferrer, the Forest Research Institute, Gedeon Richter, GlaxoSmith-Kline, Janssen, Janssen-Cilag, Jazz, Johnson\&Johnson, Lundbeck, Merck, Novartis, Organon, Otsuka, Pfizer, Pierre-Fabre, Qualigen, Roche, Sanofi-Aventis, Schering-Plough, Servier, Shire, Solvay, Takeda, Teva, CIBERSAM, the Seventh European Framework Programme (ENBREC), the Stanley Medical Research Institute, United Biosource Corporation, and Wyeth. No other conflicts of interest declared concerning the publication of this article.

\section{References}

1. Torres IJ, Boudreau VG, Yatham LN. Neuropsychological functioning in euthymic bipolar disorder: a meta-analysis. Acta Psychiatr Scand Suppl. 2007;116:17-26.

2. Bora E, Yucel M, Pantelis C. Cognitive endophenotypes of bipolar disorder: A meta-analysis of neuropsychological deficits in euthymic patients and their first-degree relatives. J Affect Disord. 2009;113:1-20.

3. Burdick KE, Russo M, Frangou S, Mahon K, Braga RJ, Shanahan $M$, et al. Empirical evidence for discrete neurocognitive subgroups in bipolar disorder: clinical implications. Psychol Med. 2014;44:3083-96

4. Solé B, Jiménez E, Torrent C, Del Mar Bonnin C, Torres I, Reinares M, et al. Cognitive variability in bipolar II disorder: WHO is cognitively impaired and who is preserved. Bipolar Disord. 2016;18:288-99.

5. Reinares M, Colom F, Rosa AR, Bonnín CM, Franco C, Solé B, et al The impact of staging bipolar disorder on treatment outcome of family psychoeducation. J Affect Disord. 2010;123:81-6.

6. Demant KM, Vinberg $M$, Kessing L V, Miskowiak KW. Assessment of subjective and objective cognitive function in bipolar disorder: Correlations, predictors and the relation to psychosocial function. Psychiatry Res. 2015;229:565-71.

7. López-Jaramillo C, Lopera-Vásquez J, Gallo A, Ospina-Duque J, Bell V, Torrent C, et al. Effects of recurrence on the cognitive performance of patients with bipolar I disorder: implications for relapse prevention and treatment adherence. Bipolar Disord. 2010;12:557-67.

8. Martinez-Aran A, Scott J, Colom F, Torrent C, Tabares-Seisdedos $R$, Daban $C$, et al. Treatment nonadherence and neurocognitive impairment in bipolar disorder. J Clin Psychiatry. 2009;70:1017-23.

9. Martinez-Aran A, Vieta E. Cognition as a target in schizophrenia, bipolar disorder and depression. Eur Neuropsychopharmacol. 2015;25:151-7.

10. Miskowiak KW, Petersen JZ, Ott CV, Knorr U, Kessing LV, Gallagher $P$, et al. Predictors of the discrepancy between objective and subjective cognition in bipolar disorder: a novel methodology. Acta Psychiatr Scand. 2016;134:511-21.

11. Rosa AR, Mercadé C, Sánchez-Moreno J, Solé B, Mar Bonnin C Del, Torrent $C$, et al. Validity and reliability of a rating scale on subjective cognitive deficits in bipolar disorder (COBRA). J Affect Disord. 2013;150:29-36.

12. Jensen JH, Støttrup MM, Nayberg E, Knorr U, Ullum H, Purdon $\mathrm{SE}$, et al. Optimising screening for cognitive dysfunction in bipolar disorder: Validation and evaluation of objective and subjective tools. J Affect Disord. 2015;187:10-9.

13. Broadbent DE, Cooper PF, FitzGerald P, Parkes KR. The Cognitive Failures Questionnaire (CFQ) and its correlates. Br J Clin Psychol. 1982;21:1-16

14. Chelune GJ, Heaton RK, Lehman RAW. Neuropsychological and personality correlates of patients' complaints of disability. In: Goldstein G, Tarter R, editors. Advances in clinical neuropsychology. New York: Plenum; 1986. p. 95-126.

15. Cuesta MJ, Peralta V, Irigoyen I. Factor analysis of the Frankfurt Complaint Questionnaire in a Spanish sample. Psychopathology. 1996;29:46-53.

16. McNair D, Kahn RJ. Self-assessment of cognitive deficits. In: Crook T, Ferris S, Bartus R, editors. Assessment in geriatric psychopharmacology. New Canaan: Mark Powley; 1983. p. 13743.

17. Xiao L, Lin X, Wang Q, Lu D, Tang S. Adaptation and validation of the "cognitive complaints in bipolar disorder rating assessment" (COBRA) in Chinese bipolar patients. J Affect Disord. 2015;173:226-31.

18. Ott $C V$, Bjertrup $A J$, Jensen $\mathrm{JH}$, Ullum $\mathrm{H}$, Sjælland $\mathrm{R}$, Purdon $\mathrm{SE}$, et al. Screening for cognitive dysfunction in unipolar depression: Validation and evaluation of objective and subjective tools. J Affect Disord. 2016;190:607-15.

19. Toyoshima K, Fujii Y, Mitsui N, Kako Y, Asakura S, Martinez-Aran A, et al. Validity and reliability of the Cognitive Complaints in Bipolar Disorder Rating Assessment (COBRA) in Japanese patients with bipolar disorder. Psychiatry Res. 2017;254:85-9.

20. Hamilton M. A rating scale for depression. J Neurol Neurosurg Psychiatry. 1960;23:56-62.

21. Young RC, Biggs JT, Ziegler VE, Meyer DA. A rating scale for mania: reliability, validity and sensitivity. Br J Psychiatry. 1978;133:42935.

22. Rosa AR, Sánchez-Moreno J, Martínez-Aran A, Salamero M, Torrent $C$, Reinares $M$, et al. Validity and reliability of the Functioning Assessment Short Test (FAST) in bipolar disorder. Clin Pract Epidemiol Ment Heal. 2007;3:5.

23. Yatham LN, Torres IJ, Malhi GS, Frangou S, Glahn DC, Bearden $\mathrm{CE}$, et al. The International Society for Bipolar Disorders-Battery for Assessment of Neurocognition (ISBD-BANC). Bipolar Disord. 2010;12:351-63.

24. Tombaugh TN, Kozak J, Rees L. Normative data stratified by age and education for two measures of verbal fluency: FAS and animal naming. Arch Clin Neuropsychol. 1999;14:167-77.

25. Reitan RM. Validity of the trail making test as an indication of organic brain damage. Percept Mot Skills. 1958;8:271-6.

26. Wechsler D. The Wechsler Adult Intelligence Scale-III (WAISIII) administration and scoring manual. San Antonio: The Psychological Corporation; 1997. 
27. Wechler D. Escala de Inteligencia Wechsler para Adultos-III (WAIS III) - Manual técnico. São Paulo: Casa do Psicólogo; 2001. 412 p. (Nascimento $\mathrm{E}$, editor.)

28. Benedict RHB, Schretlen D, Groninger L, Brandt J, Benedict RHB, Schretlen D, et al. Hopkins Verbal Learning Test - Revised: normative data and analysis of inter-form and test-retest reliability. Clin Neuropsychol. 1998;12:43-55.

29. Golden CJ. Stroop Colour and Word Test. Chicago: Stoelting; 1978.

30. Sanvicente-Vieira B, Kluwe-Schiavon B, Wearick-Silva LE, Piccoli $\mathrm{GL}$, Scherer L, Tonelli HA, et al. Revised Reading the Mind in the Eyes Test (RMET) - Brazilian version. Rev Bras Psiquiatr. 2014;36:60-7.

31. Wechsler D. Wechsler Abbreviated Scale of Intelligence. New York: The Psychological Corporation/Harcourt Brace \& Company; 1999.
32. Wechsler D. Escala Wechsler Abreviada de Inteligência - WASI: Manual. São Paulo: Casa do Psicólogo; 2014. 488 p. (Trentini CM, Yates DB, Heck VS, editors.)

\section{Correspondence:}

Adriane R. Rosa

Laboratório de Psiquiatria Molecular, Hospital de Clínicas de Porto Alegre

Rua Ramiro Barcelos, 2350

90035-903 - Porto Alegre, RS - Brazil

Tel.: +55 (51) 33598845

E-mail: adrianerrosa@gmail.com 
Appendix 1 - Portuguese and English versions of the Cognitive Complaints in Bipolar Disorder Rating Assessment (COBRA)

\section{Portuguese version}

Escala de Disfunções Cognitivas no Transtorno Bipolar

(COBRA)

1. Você tem dificuldade para se lembrar do nome das pessoas?

2. Você tem dificuldade para encontrar objetos de uso diário (chaves, óculos, relógio)?

3. Você tem problemas para se lembrar de acontecimentos que foram importantes na sua vida?

4. É difícil para você situar no tempo determinados acontecimentos?

5. É difícil para você se concentrar na leitura de um livro, ou jornal?

6. É difícil para você se lembrar do que você leu, ou do que the disseram, recentemente?

7. Você tem a sensação de que não termina o que começou?

8. Você tem executado de forma mais lenta as tarefas do dia-adia?

9. Você já se desorientou alguma vez na rua?

10. Quando alguém relembra uma conversa, ou comentário, que teve com você; você tem a impressão de estar ouvindo a informação pela primeira vez?

11. É difícil para você, em algumas ocasiões, encontrar as palavras certas para expressar as suas ideias?

12. Você se distrai com facilidade?

13. É complicado para você fazer cálculos simples mentalmente?

14. Você tem a impressão de perder o rumo da conversa?

15. Tem sido difícil para você aprender novas informações?

16. É difícil para você manter a concentração em uma tarefa durante muito tempo?

0 . Nunca

1. Às vezes

2. Frequentemente

3. Sempre
English version

Cognitive Complaints in Bipolar Disorder Rating Assessment (COBRA)

1. Do you have difficulties to remember peoples' names?

2. Do you have difficulties to find objects of daily use (keys, glasses, wristwatch)?

3. Do you find it difficult to remember situations that were important to you?

4. Is it hard for you to place important events in time?

5. Do you find it hard to concentrate when reading a book or a newspaper?

6. Do you have problems recalling what you have read or have been told recently?

7. Do you have the feeling that you do not finish what you begin?

8. Does it take you longer than normal to complete your daily tasks?

9. Have you ever felt disoriented in the street?

10. When people remind you of a conversation or a comment you heard, do you get the impression that it is the first time you hear it?

11. Is it sometimes difficult for you to find the words to express your ideas?

12. Are you easily distracted?

13. Do you find it hard to do simple mental calculations?

14. Do you get the impression that you cannot follow a conversation?

15. Have you noticed that you find it difficult to learn new information?

16. Do you struggle to keep focused on a particular task for a long time?

0. Never

1. Sometimes

2. Often

3. Always 